\title{
OPTIMISING FORKLIFT ACTIVITIES IN WIDE-AISLE REFERENCE WAREHOUSE
}

\author{
Burinskiene, A. \\ Faculty of Business Management, Sauletekio ave. 11, Vilnius, LT-10223, Lithuania \\ E-Mail: aurelija.burinskiene@vgtu.lt
}

\begin{abstract}
Nowadays the great attention has to be paid to warehouse. Theoretical analysis shows the need to optimise their activities. This encourages the search of more advanced solutions. Aiming to determine possible improvements, the operations of forklifts are examined in warehouses, and detail solutions are presented.

For empirical study author created a simulation model and tested different scenarios. First of all, author examined the new routing method and suggested programming algorithm for forklift route optimization. In the first part of the study possible improvements for put-away activity are analysed, in the second part - improvements for replenishment activity are overviewed. Simulation results showed that the reduction of forklift travel distance is equal from $11.1 \%$ to $35.6 \%$. Finally, the study ends with detail suggestions: author presented new routing method and forklift routing algorithm. Further, the theoretical results have to be tested in practise.

(Received in December 2014, accepted in May 2015. This paper was with the author 2 months for 2 revisions.)
\end{abstract}

Key Words: Warehouse, Forklifts, Routing, Simulation, Performance Analysis

\section{INTRODUCTION}

Warehouses are becoming critical for trade enterprises to outperform competitors on productivity, costs. So, low costs and high productivity are considered in many warehouses as a competitive weapon. $75 \%$ of warehouses retrieve products manually. For warehouse operations, forklifts are the most expensive machines. Requirements for forklifts and costs for operation are crucial in such warehouses.

Forklifts are the most expensive machines due to investments in equipment and other assets, which are used to support their operations. This shows the importance of such research. In addition, the analysis of scientific literature, which is published by Oxford University Press, Cambridge University Press, Harvard University Press, Springer, M.E. Sharpe, Routledge, etc. shows that only $3.7 \%$ of authors, which analyse warehouse issues, give attention to forklifts. The authors that analyse the operations of forklifts revise how to manage resource operation by integrating RFID or how to optimize travelling by implementing multiple-tasks approach in warehouse. The implementation of RF-based process and the application of multiple-tasks are treated as advanced solutions seeking to increase productivity. On the other hand, scientific knowledge of circumstances and scientifically proved solutions should be used to determine the effect of such applications. The studies of second direction deliver $9 \%$ savings in productivity.

In the paper author analyses the optimisation of forklifts in wide-aisle warehouse seeking to examine the new routing method and, in case of positive effect, to suggest programming algorithm for forklift route optimization. In order to determine potential savings, a simulation model is created. After simulation, results showed that the reduction of forklift travel distance is equal to one-third.

The target of the paper - to determine possible improvements in forklifts operations. To answer the above-mentioned question, study is presented in the paper. The study is divided into two parts. At the beginning literature review is given, later on an experimental study is 
presented. A literature review is a summary of the application of forklifts in trading companies. The first part of the study is dedicated for the identification of forklift and construction of least-costs operations. Moreover, the second part - to the presentation of detail solutions is including programming algorithm for forklift route optimization.

The study is based on simulation, comparative analysis methods.

\section{THE SCOPE OF FORKLIFTS APPLICATION IN WAREHOUSES}

\subsection{Forklift operations}

When purchasing a forklift, the purchaser must know if it can meet handling needs of the company. This is where productivity comes in. Speed limits are applicable, and they have huge impacts. Usually, manufacturers of forklifts can design governors on velocities that only allow reaching the certain speed [1].

The speed limit in different warehouses is $10 \mathrm{~km} / \mathrm{h}$. A forklift is a powerful tool when used by well-trained operator. It helps to move pallets (or other materials) by eliminating the need to lift and carry boxes by hands. Forklifts can be classified by different methods including the power source, operator position, and load engagement method. Electric motors powered by batteries are among the most common type of forklifts seen in the industry [1]. Different manufacturers may offer different models of forklifts. Selection of forklift is often a several-step decision process. First characteristic is volume of material flow - the large volume will require buying the number of forklifts with similar characteristics. Second characteristic is the frequency and scheduling of movements - this relates to the time between changes. Usually, movements are performed due to different batches or continuous. Third characteristic is route factor - this includes distance, conditions along the route, and the path of travel [2]. In addition, there are important forklift selection factors: purchasing price, operating costs, maintenance costs [2]. The regulation requires that a forklift be checked every day that the forklift is used. If the forklift is used continuously, then it must be checked at the end of each shift.

Forklift operations require the floor space as well. Traditional wide-aisle pallet storage aisles must have corridors 3.3-3.6 m for forklifts operations. It is necessary to have also barriers that protect walls and racks against forklift damages.

The place of depot in front of aisles or between the two blocks is planned in Caron et al. (1998) study. This is the position where forklift operator takes task and after which returns back for another one [3]. The number of locations available in storage area usually is smaller than the total number of pallets arriving at warehouse on a daily basis. This means that first, pallets from storage places have to be removed to picking places and after this, and new pallets can be placed to storage area. In the end, this means increased throughput time per order.

There are several ways to develop forklifts operations by applying RFID (Fig. 1): (1) the recognition and visibility of products. Today is the predominant focus on tracking (i.e. recognition and visibility of an object by using a unique ID) [4]; (2) the replacement of manual data collection to the automatic collection. The seamless flow of information can be created with automatic application only [5]; (3) the automation of process. RFID is considered to have potential to improve the efficiency and accuracy of many processes [6]. First, RFID automates labour-intensive work; second, it gives the ability to eliminate human mistakes [7]. There are traditional activities delivered with forklifts:

- Receiving activity. Forklifts are used for unloading pallets at the receiving docks. If there is a tag at doors it can help to get real time (on-line) information about received pallets and quantities; 
- Put-away activity. Forklifts linked to RFID can be used for the identification of locations and can help to get dynamic data about stocks in locations. This gives real time (on-line) updates on stock availability in the reserve and pick locations or information about pallets, which are moved from one door to another and are ready to be shipped in case of X-dock operations;

- Replenishment (refill) activity. Forklifts and RFID can be used to increase control on stock availability at locations and to eliminate no stock (out-of-stock) problems. Automatic replenishment activity not new, but the usage of RFID can help to improve the accuracy of the process [8];

- Picking full pallets activity. Forklifts and RFID can be used for the identification of locations and the elimination of stock form location at the same time;

- Shipping activity. Forklifts and RFID can be used for shipping pallets. After loading to truck operations was finished, the dispatch manifests are generated.

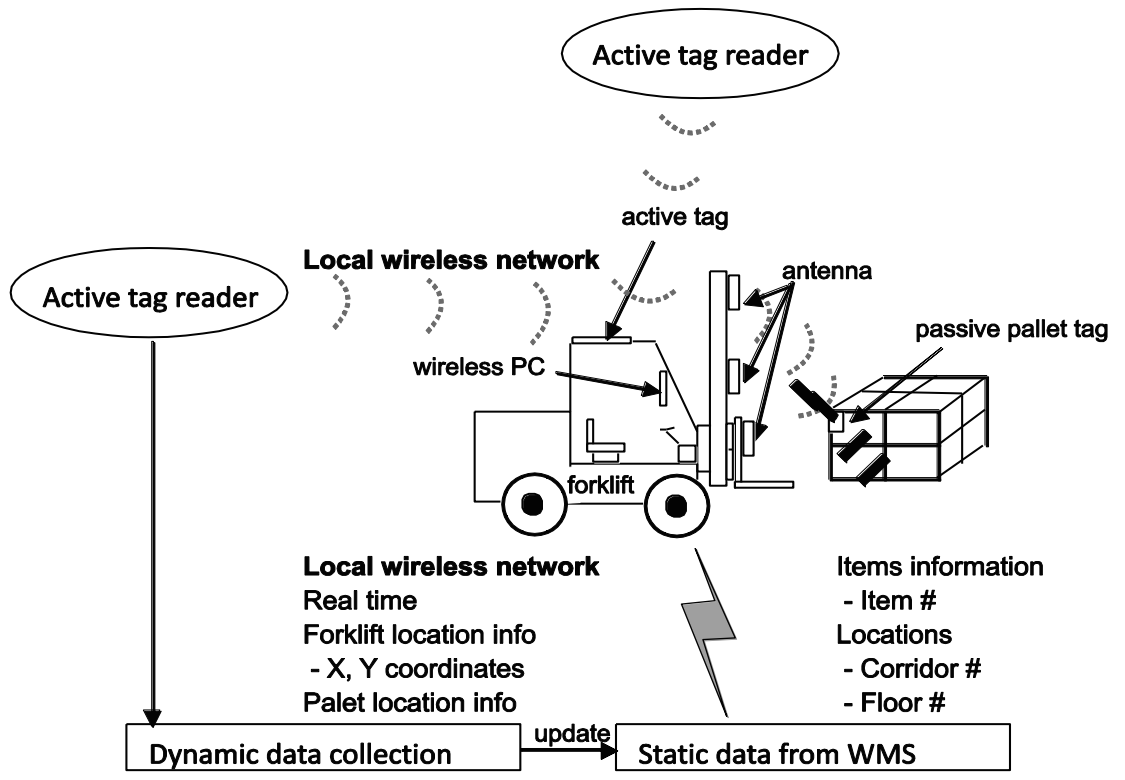

Figure 1: Forklift linked to the system.

The travel time in a warehouse, in general, has a significant impact on throughput time. The time, needed for forklifts operations can be split in travel time (travelling time), pick and place time and remaining time. The travel time is required for the movement between locations that have to be visited (where the items are stored that have to be moved). The pick time is associated with stop, finding and picking right pallet. This includes search for the pallet, grabbing it, scanning it and storage location, reading the next location to be visited. Place time is related to the dropping of the pallet to pick location and scanning it.

The remaining time is related to time needed to close the task, get next assignment, etc.

\subsection{Forklift routing algorithms}

$50 \%$ of the total travel time is spent on unproductive traveling [9]. Saving algorithms are based on the algorithm of Clarke and Wright (1964) for the vehicle routing problem: a saving on travel distance is obtained by combining a set of small tours into a smaller set of larger tours [10]. Timesaving that can be obtained if different tasks are combined instead of being executed separately. For combined tasks, the time saving is calculated. Instructions for the next route are given via a computer terminal [11].

For reaching next assignment, radio data terminal is used by forklift operator. The forklift operator follows a route designated by reading instructions on the radio data terminal or 
following commands. Each route is formed containing many tasks. This process is repeated until all tasks while day has been assigned to a route.

All articles discussed so far assume that the aisles of the warehouse are narrow enough allowing retrieving pallets from both sides of the aisle without changing position. In Goetschalckx and Ratliff (1988), a polynomial-time optimal algorithm is developed that solves the problem of routing order pickers in wide-aisles [12].

In the calculation of the timesaving, a routing algorithm may be used. This may be one of the mentioned heuristics: S-shape, Combined, Largest gap, return, mid-point, etc. or optimal [11]. Usually, the optimal method outperforms S-shape method by 7-33\% in single-block random storage warehouses [13]. Several types of the above-mentioned algorithms are discussed in De Koster et al. (1999) [14].

In practice, usually simple routing heuristics is used. Not standard warehouse management system WMS consists that contains the Ratliff and Rosenthal algorithm. Methods that are used include the 'Largest gap' return strategy, 'Mid-point' return strategy, 'S-shape' strategy. In the application of 'S-shape' algorithm, a distinction has to be made between single side and double-side picking [14]. In addition, tracking system may be used that will connect forklifts to the mobile device for the provision of routing information [15].

Eastern Service Company - freight forwarding and logistics service provider in Hong Kong and South China. The company specializes in managing warehouses and providing other cargo logistics services. This company aims to achieve these major service goals to their customers: shorten the lead-time, and maintain a higher visibility on the supply chain area. To ensure accuracy scanning is applied to check the right correctness of movement [16].

In many labour-intensive warehouses, there is the constant pressure to reduce travelling time. One of such is Bijenkorf warehouse - warehouse of retail trade organization in Holland with the product assortment of 300 thousand stock-keeping units. De Koster et al. (1999) have made the case study analysis. Delivered results are as follows: the reduction of total travel time means reduction in the number of labour units [14].

Another problem with routing may arise if products are stored at multiple locations in a warehouse [11]. In this case, a choice by warehouse management system has to be made before directing the forklift to location from which the pallet has to be retrieved.

The travel time is an increasing function of the travel distance (study, for example, [1719]). Consequently, the travel distance is considered often for planning warehouse.

Two types of travel distance are widely used in appropriate literature: the average travel distance of the tour (or average tour length) and the total travel distance. For a given tasks list (a set of tasks), however, minimizing the average tour length is equivalent to minimizing the total travel distance.

Clearly, the minimization of average travel distance (or, equivalently, total travel distance) is limited for forklift operations. Usually, it is only one of many possibilities. Another important objective would be minimizing the total cost [11] (that may include both investments into forklifts and related infrastructure and operational costs).

\section{EMPIRICAL STUDY}

The objective of empirical study is to find out possible improvements helping to deliver leasttravel forklift solutions.

The first part of empirical study is dedicated for searching possible improvements for putaway activity. The second part of empirical study is for searching potential improvements for replenishment activity. For such one-month data is uploaded in to simulation model.

The structure of the Excel-based simulation model is based on warehouse layout and simulation. 
Warehouse layout. A schematic picture of the wide-aisle warehouse is shown in Fig. 2. The width of aisles is $5 \mathrm{~m}$. The items (each item with one picking location) are stored on shelves and are picked in cases from picking locations.

The considered warehouse, called a reference warehouse, has eight parallel aisles, and each aisle contains one hundred picking locations (the width of each location is 0.8 and the length $-1.2 \mathrm{~m}$ ). The cross-aisle in the middle of the warehouse separates it into two storage blocks and makes three possibilities of switching between aisles: at the front, at the rear and in the middle. The width of middle cross-aisle is $4.8 \mathrm{~m}$, and it is used in the reference warehouse to handle the traffic. In reference warehouse, the total width of the aisle is $3.4 \mathrm{~m}$.

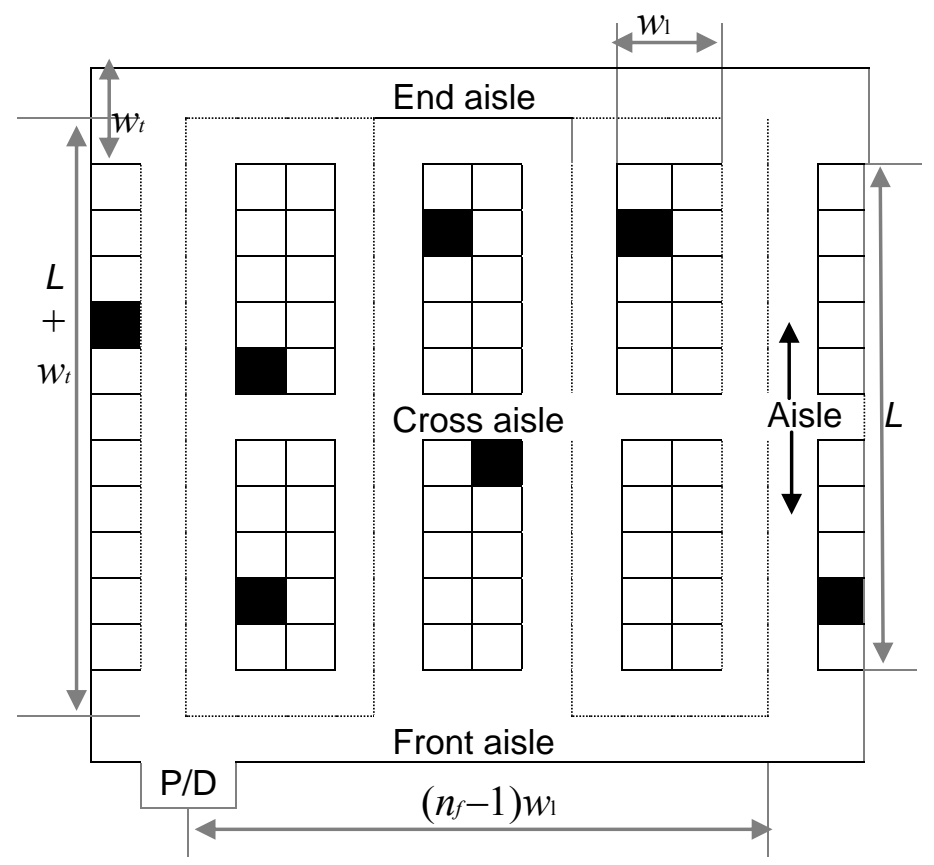

Figure 2: Layout of wide-aisle warehouse (black - picking order, P/D - depot).

The travelling inside wide-aisle is integrated with forklift route.

Simulation on warehouse layout. Simulation on warehouse layout uses the database of activities, where sequences of locations visited are defined; as well activity in accordance with the next activity. It is also considered that the velocity travels in warehouse at the same speed.

The movements such as forklift inside aisles, cross-aisles are modelled by Visual Basic macro (VBA) commands. Three macro command blocks are used for the algorithm: (1) the first two command blocks - for moving between even or odd locations. The forklift is moving according to the schematic picture of the reference warehouse. During the simulation, the forklift is moving at the right side of the corridor and is stepping to the left side by activity request only; (2) the third command block - for taking different activity.

If the forklift moves between different aisles for any purposes (to pick pallets) the algorithm checks which cross-aisle is closer to the previous and next locations, and indicates the closest cross-aisle for the next forklift's movement (Fig. 3).

The macro command is also used to calculate total travel distance. It is considered that inside the aisle, the forklift is travelling $0.3 \mathrm{~m}$ away from the shelves. When a forklift is retrieving a pallet, $0.3 \mathrm{~m}$ till location and $0.3 \mathrm{~m}$ back are added to the total travel distance. If the forklift is changing from the right side of the aisle to the left side or from the left to the right side, the distance of $2.8 \mathrm{~m}$ for changing sides is added. The calculation of total travel distance is activated by pressing the VBA command button. 


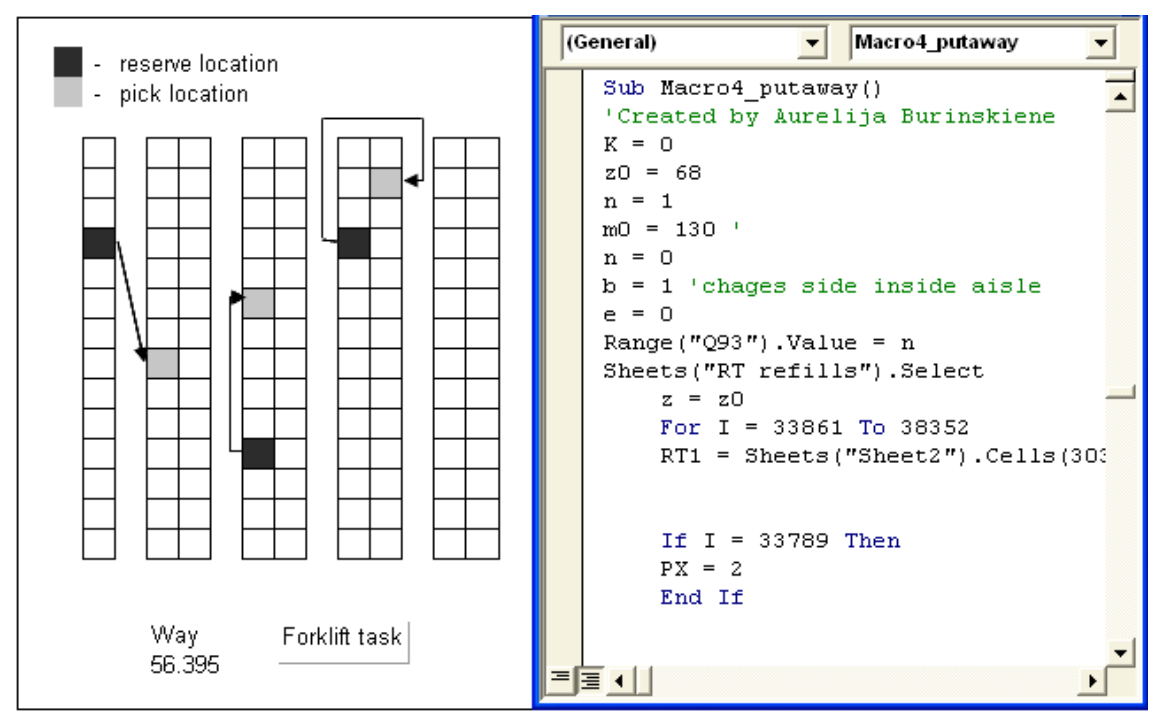

Figure 3: The Excel simulation model: warehouse layout on the left side and command algorithm on the right side [20].

Validation tests show that (1) the simulated model meets real processes that occur in an ordinary warehouse. Tasks lists were created based on the date, tasks, and locations visits identification numbers; (2) in reality, many forklifts are working, but the calculation of travel distance implemented in the simulation model represents summarised travel distances of all forklifts; (3) practically the forklift operator can return to the depot through different crossaisles or aisles. In that case, the total travel distance can be the same or longer as the macro command algorithm is choosing the shortest way.

\subsection{Results of empirical tests}

The author investigated that put-away and replenishment tasks take the highest number of forklifts' tasks. 1000 tasks consists of 393 put-away tasks, 319 replenishment tasks, 38 picking full pallets, 250 of them are shipping tasks. So, first, put-away activity is analysed, later on replenishment activity. For such all forklift tasks are entered into the simulation model.

First, simulation tests showed that seeking to improve put-away activity there is a need to re-design inbound process. To allocate inbound supplier in front of storage aisle (this means that the cardinal revision of supplier's delivery plan is required).

Second, simulation tests also showed that seeking to improve replenishment activity there is the need to implement new ,broom effect" solution (as it shows highest reduction in total travel distance; in general, the total travel distance is reduced by $11.1-12.9 \%$ ).

Such results deliver big improvement: in total both solutions brings $35.6 \%$ improvement in forklifts travel distance. These solutions are described below more details.

Put-away activity. The allocating of supplier in front of the aisle (which has a maximum number of put-away) method gives $80 \%$ optimization but requires changes in inbound plan.

In reference warehouse, only $27 \%$ of pallets are received in front of storage aisles or close to them, (these are the aisles where the pallets will be placed by forklift after receiving). The constructed aim - receive $56 \%$ or more pallets in front of aisles or close to aisles, where this pallet will be stored when receiving activity is finished.

In reference warehouse, inbound and outbound doors are allocated on different sites of warehouse, when improvement in a single activity could be reached with changes in supplier's delivery plan.

Supplier's delivery plan is time schedule where each supplier has his delivery time, unloading door number, unloading start and end time. Mentioned time frame is calculated for 
each supplier taking into account the number of delivered pallets or the number of delivered articles. Period is calculated for a specific period taking the max number of delivered pallets or articles (the second one is used for the suppliers delivering low volume items).

\begin{tabular}{|l|l|l|c|c|c|c|c|}
\hline \multicolumn{3}{|c|}{ Time for } & \multicolumn{2}{c|}{ Pallets } & \multicolumn{2}{|c|}{ Articles } & Place \\
\hline Delivery & Unloading & Supplier title & Aver. & Max & Aver. & Max & Aisle \\
\hline $7: 00$ & 1,71 & Beer & 39 & 93 & 3 & 3 & H \\
\hline $7: 30$ & 0,04 & Julce & 85 & 178 & 40 & 80 & F \\
\hline $8: 00$ & 0,03 & Soft drink & 26 & 57 & 15 & 30 & F \\
\hline $8: 00$ & 0,02 & Sugar & 15 & 27 & 5 & 7 & D \\
\hline
\end{tabular}

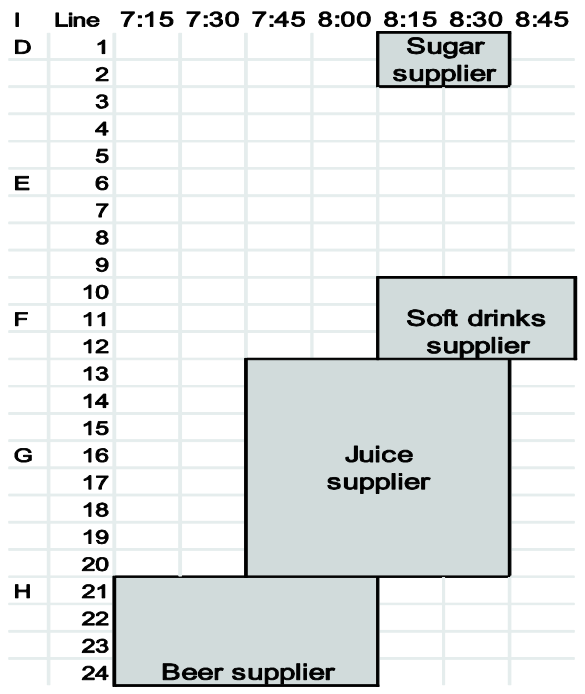

Figure 4: A fragment from constructed plan (left side - the period of suppliers, right side - schematic plan).

Reference warehouse has issues with receiving beer suppliers, soft drink producers, and sugar distributors (only $3.7 \%$ of soft-drink pallets, $3.9 \%$ of beer pallets, and $24.6 \%$ of sugar pallets are received in front of storage aisles or close to them). The volume of these products constructs $46 \%$ of all inbound volume.

To get improvement for the implementation of the new inbound plan such rules are suggested: (1) on conflict situations, priority is given for bigger supplier; (2) max. unloading period is taken for supplier; (3) unloading space is calculated for each supplier taking into account that ten pallets fit single receiving line.

After detailed revision, the new suppliers delivery plan is constructed (Fig. 4).

Replenishment (refill) activity. Simulation results show that forklifts are driving $69 \%$ of the distance with empty forks.

Author checked that the most of replenishment activities are manually requested. During the day, $32.5 \%$ of all replenishment activities are requested manually; others - requested by system after all picking lists are printed or activated by individual pickers. In reference warehouse, this issue is quite common because all customers' orders are printed at once.

Due to this replenishment can be organized based on two approaches: (1) urgent replenishment of product (manually requested), which is "out of stock" in the pick area; (2) replenishment of products, which have less than one day stock in the pick area.

Author also tested zoning strategy. If the warehouse is divided into two zones, $8.1 \%$ reduction in forklift travel distance is received.

Author identified that at the same aisle, where is already working one forklift in five minutes, coming second forklift. If first forklift is taking both mentioned tasks in the aisle author reached $2.8 \%$ reduction in forklifts travel distance.

Author tested the routing improvement strategy - if once per hour forklift is coming to the aisle and does all replenishment tasks, $11.1-12.9 \%$ reduction in forklift travel distance is reached. This effect is called „broom effect“ and outcome of process-based routing method used for forklifts trip optimization.

In reference warehouse, constant velocity speed is equal to $3.0 \mathrm{~m} / \mathrm{s}$ with payload (on average $420 \mathrm{~kg}$ ) and without; forklift operates always indoor. 
Couple of additional tests, which results show that highest reduction in travel distance is reached from solution called „,broom effect": (1) If within hour forklift replenishes all locations inside aisles for the first time, later on - all locations inside the aisle for the second time and etc.; these replenishments are started from the closest to depot locations in each aisle; savings are equal to $11.1 \%$ of travel distance; (2) If forklift operator works on his tasks in period sequence (day, hour); these replenishments are started from the closest to depot locations in each aisle; savings are $12.9 \%$ of travel distance.

Author also found that in reference warehouse $46 \%$ of replenishment activities are done together with the return to storage operations. Such activity could be added to the list of traditional forklift activities. This topic could be revised in further investigations.

Table I: Notations.

\begin{tabular}{|l|l|l|l|}
\hline$C p$ & Index for priority & $X, Y, Z$ & Coordinates of forklift \\
\hline$r_{t, 2 ; ;, n}$ & $\begin{array}{l}\text { Forklifts (in Appendix reach truck id } \\
- \text { RTID) }\end{array}$ & $X_{s, t,} Y_{s, t, Z_{s, t}}$ & Coordinates of locations \\
\hline$D^{s t}$ & $\begin{array}{l}\text { Distance between two successive task } \\
\text { locations }(s, t-\text { locations) }\end{array}$ & $X_{a l ; a 2 ; ; a_{n} ; Y_{a l ; a z ; ; a_{n}}}$ & Coordinates of cross-aisles \\
\hline
\end{tabular}

\subsection{Current system model}

In the reference warehouse, the formula in existing information management system is constructed according such logic used in Eq. (1):

$$
\operatorname{Min}\left(D_{r_{1}}^{s t}, D_{r_{2}}^{s t}, \ldots, D_{r_{n}}^{s t}\right) \cdot<0 ; 1>+\left|Y_{s}-Y_{t}\right| \cdot<1 ; 0>+\left|X_{s}-X_{t}\right|+\left|Z_{s}-Z_{t}\right|+C_{p}
$$

The formula works if $C_{p}=0$.

$<0 ; 1>$ : aisles $l_{0}=l_{1}>0 ; l_{0}=/=l_{1}->1$;

$<1 ; 0>$ : aisles $l_{0}=l_{1}->1 ; l_{0}=/=l_{1}->0$.

\section{SUGGESTED SYSTEM MODEL}

The system architecture supports the decision-making process [21] on forklift management.

The author suggested incorporating broom replenishment (refill) logic into the system. The underlying brief algorithm, which is developed in by the author, is provided next.

The one that has the shortest trip is selected as illustrated in equation (2), which is based on Lawler et al. (1985) [22]. The Eq. (2) is followed by mathematical solution (3):

$$
\operatorname{Min}\left(D_{r_{1}}^{s t}, D_{r_{2}}^{s t}, \ldots, D_{r_{n}}^{s t}\right)
$$

where:

$$
D^{s t}=\left|X_{s}-X_{t}\right|+\left|Z_{s}-Z_{t}\right|+\min \left\{\begin{array}{c}
\left|Y_{s}-Y_{a_{1}}\right|+\left|Y_{a_{1}}-Y_{t}\right| ; \\
\left|Y_{s}-Y_{a_{2}}\right|+\left|Y_{a_{2}}-Y_{t}\right| ; \\
\vdots \\
\left|Y_{s}-Y_{a_{n}}\right|+\left|Y_{a_{n}}-Y_{t}\right|
\end{array}\right\} \begin{gathered}
\text { IF cross aisle } 1 \\
\text { IF cross aisle } 2 \\
\vdots \\
\text { IF cross aisle } n
\end{gathered}
$$

$\left|Z_{s}-Z_{t}\right|=1$, if forklift $r$ goes from location $s$ to location $t$; otherwise 0 .

Author also delivered practical application of suggested model. Three locations K094-3, K023-2, L094-3 were used to test the model:

K094-3: $X_{s}=45.8 ; Y_{s}=43.102 ; Z_{s}=1.79$; K023-2: $X_{t}=41.4 ; Y_{t}=10.307 ; Z_{t}=1.52$;

L094-3: $X_{t 1}=40.1 ; Y_{t 1}=43.102 ; Z_{t 1}=1.79$; $Y_{a 1}=0 ; Y_{a 2}=70 ; Y_{a 3}=140$. 


$$
D^{s t}=|45.8-41.4|+|1.79-1.52|+\min \{|43.102-70|+|70-10.307|\} \text { IF cross aisle } 2
$$

IF cross aisle $2: \quad D^{s t}=4.4+0.27+32.795=37.465 ; \quad D_{1}^{s t}=5.7+0+53.796=59.496$

It is evident that $Z$ coordinates do not change the driving distance of forklift only forklift forks are moved accordingly. Therefore, $Z$ coordinates should only be taken into consideration in replenishment cases for searching the closest return to storage location to replenished one. In reference warehouse, tested formula shows double calculation of some parts of the distance, such as presented in second case bellow:

$$
\begin{gathered}
\operatorname{Min}\left(D_{r_{1}}^{s t}, D_{r_{2}}^{s t}, \ldots, D_{r_{n}}^{s t}\right) \cdot<0 ; 1>+\left|Y_{s}-Y_{t}\right| \cdot<1 ; 0>+\left|X_{s}-X_{t}\right|+\left|Z_{s}-Z_{t}\right|+C_{p} \\
\operatorname{Min}(37.465,59.496) \cdot<0 ; 1>+|43.102-10.307| \cdot<1 ; 0>+4.4+0.27+0=37.465
\end{gathered}
$$

Inside the aisle if locations are changing from left to the right side, this do not mean that forklift first has to replenish locations on the right side and later on - on the left side. Inside the aisle the position of forklift always is the mid of the aisle, so it should not be the difference in case the location in another side is further because of $X$. The final Eq. (4) is suggested for shortest distance analysis in reference warehouse:

$$
D^{s t}=\left|X_{s}-X_{t}\right|+\min \left\{\begin{array}{c}
\left|Y_{s}-Y_{a_{1}}\right|+\left|Y_{a_{1}}-Y_{t}\right| ; \\
\left|Y_{s}-Y_{a_{2}}\right|+\left|Y_{a_{2}}-Y_{t}\right| ; \\
\vdots \\
\left|Y_{s}-Y_{a_{n}}\right|+\left|Y_{a_{n}}-Y_{t}\right|
\end{array}\right\} \begin{gathered}
\text { IF cross aisle } 1 \\
\text { IF cross aisle } 2 \\
\vdots \\
\text { IF cross aisle } n
\end{gathered}
$$

In addition, author suggested forklift routing algorithm for "broom effect" implementation in reference warehouse. Such algorithm is placed in Appendix 1. The above-mentioned formula is incorporated into block ' $r f$ 04' and has to be used to deliver "broom refills list" for each forklift. Tests results shows that demand of forklifts grows in particular aisles at particular time, but inventory level at particular time increased and influence higher picking performance.

The tests results show correlation between inaccurate stock in locations and the unnecessary forklift travel distance to refill picking locations, which are out-of-stock (Fig. 5).

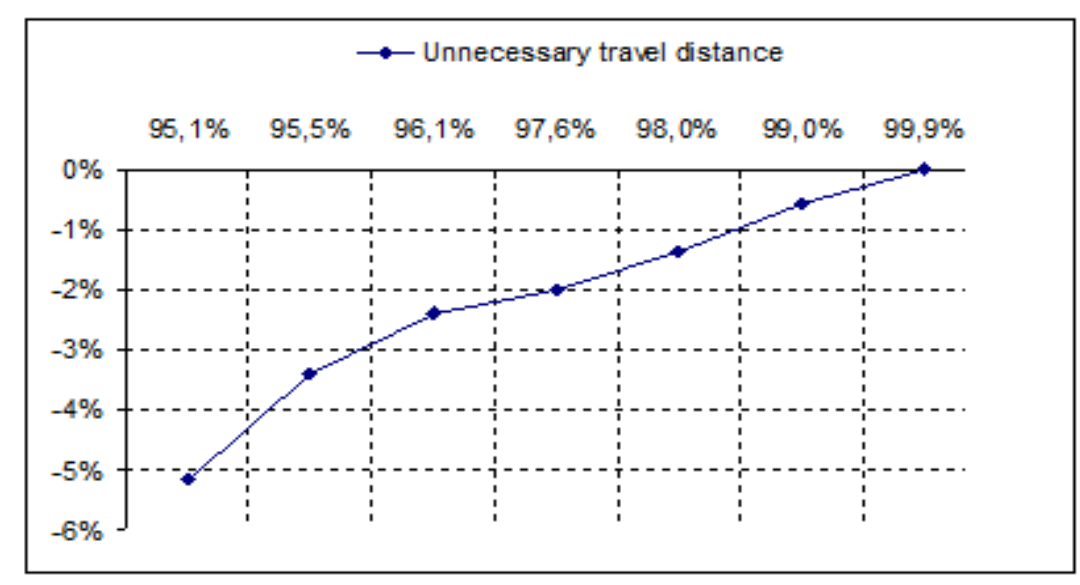

Figure 5: The reduction of travel distance and improved stock level in picking locations ( $\mathrm{x}$ axe $-\%$ of locations, $\mathrm{y}$ axe - the reduction of travel distance, \%).

The final results showed that the travel distance of forklift have been reduced by $5.2 \%$ during the day when $4.9 \%$ of out-of-stocks (49 out-of-stock cases for first 1000 tasks) were improved. 


\section{CONCLUSION}

In the paper, Excel-based warehouse environment is introduced in order to minimize total travel distance of forklifts. For optimizing, the forklift's put-away and replenishment activities in reference warehouse new simulation model is created. It allows simulating different aspects of mentioned activities in wide-aisle warehouse. Simulation results showed that the potential reduction of forklift travel distance from $11.1 \%$ to $35.6 \%$.

Comparative analyse of total travel distance shows that for receiving high-volume products suppliers in reference warehouse suppliers delivery plan has to be revised in order to reach distance reduction in put-away operations.

During empirical study, potential improvements for replenishment operations are revised. Comparative analyse shows which scenario is the best one for current replenishment activities. In analysed case new process-based routing method "broom effect" showed the best results. Tests results shows that output of reorganised forklift operations influence higher picking performance. The optimal start time of picking operations have to be calculated but in general shortage level per picking order is lower.

For the optimization of forklift operations, additional revision is required. Further on, more cases have to be analysed (other traditional activities of forklifts and the return to storage cases); also the practical results reached with the implementation of suggested changes (new calculation formula, "broom effect", and new suppliers delivery plan) in the reference warehouse have to be compared with theoretical estimations presented in this paper.

Results also show that the simulation model could be used as the initial tool for the decision-making process. The provided simulation model could be used for the evaluation of different methods in a wide-aisle warehouse. Undertaken experiments have shown that presented simulation model can be applied for analysing different scenarios.

Finally, the programming algorithm for forklift route optimization is presented. Still the implementation of such in in various practice cases is suggested.

The study has its limitation, further on the revision of other constrains could be used in wide-aisle warehouse seeking to minimize the travel distance of forklifts. For example, different warehouse design could be taken into account for further inbound and put-away analysis.

\section{REFERENCES}

[1] Ryan, J. L.; Ryan, L. D. (2006). The Forklift Manual, Donegal Bay Publishing, Siloam Springs

[2] Kasilingam, R. G. (1998). Logistics and Transportation - Design and Planning, Springer Science+Business Media, Dordrecht

[3] Caron, F.; Marchet, G.; Perego, A., (1998). Routing policies and COI-based storage policies in picker-to-part systems, International Journal of Production Research, Vol. 36, No. 3, 713-732, doi:10.1080/002075498193651

[4] Varila, M.; Seppanen, M.; Suomala, P. (2007). Detailed cost modelling: a case study in warehouse logistics, International Journal of Physical Distribution \& Logistics Management, Vol. 37, No. 3, 184-200, doi:10.1108/09600030710742416

[5] Spekman, R. E.; Sweeney, P. J. (2006). RFID: from concept to implementation, International Journal of Physical Distribution \& Logistics Management, Vol. 36, No. 10, 736-754, doi:10.1108/09600030610714571

[6] Miragliotta, G.; Perego, A.; Tumino, A. (2009). A quantitative model for the introduction of RFID in the fast moving consumer goods supply chain: Are there any profits?, International Journal of Operations \& Production Management, Vol. 29, No. 10, 1049-1082, doi:10.1108/ 01443570910993483

[7] Tajima, M. (2007). Strategic value of RFID in supply chain management, Journal of Purchasing and Supply Management, Vol. 13, No. 4, 261-273, doi:10.1016/j.pursup.2007.11.001 
[8] Lorchirachoonkul, W.; Mo, J. P. T. (2010). RFID implementation with virtual infrastructures, Business Process Management Journal, Vol. 16, No. 6, 917-931, doi:10.1108/ 14637151011092991

[9] Dukic, G.; Oluic, C. (2007). Order-picking methods: improving order-picking efficiency, International Journal of Logistics Systems and Management (IJLSM), Vol. 3, No. 4, 451-460, doi:10.1504/IJLSM.2007.013214

[10] Clarke, G.; Wright, J. W. (1964). Scheduling of vehicles from a central depot to a number of delivery points, Operations Research, Vol. 12, No. 4, 568-581, doi:10.1287/opre.12.4.568

[11] De Koster, R.; Le-Duc, T.; Roodbergen, K.-J. (2006). Design and control of warehouse order picking: a literature review, ERIM Report Series Research in Management, from http://repub.eur.nl/pub/7322/, accessed on 17-11-2014

[12] Goetschalckx, M.; Ratliff, D. H. (1988). Order picking in an aisle, IIE Transactions, Vol. 20, No. 1, 531-562, doi:10.1080/07408178808966150

[13] De Koster, R.; Van der Poort, E. (1998). Routing orderpickers in a warehouse: a comparison between optimal and heuristic solutions, IIE Transactions, Vol. 30, No. 5, 469-480, doi:10.1023/A:1007599307171

[14] De Koster, R.; Roodbergen, K. J.; Van Voorden, R. (1999). Reduction of walking time in the distribution center of De Bijenkorf, Speranza, M. G.; Stähly, P. (Eds.), New Trends in Distribution Logistics, Springer, Berlin, 215-234

[15] Giaglis, G. M.; Minis, I.; Tatarakis, A.; Zeimpekis, V. (2004). Minimizing logistics risk through real-time vehicle routing and mobile technologies: Research to date and future trends, International Journal of Physical Distribution \& Logistics Management, Vol. 34, No. 9, 749764, doi:10.1108/09600030410567504

[16] Lam, C. H. Y.; Choy, K. L.; Chung, S. H. (2011). A decision support system to facilitate warehouse order fulfilment in cross-border supply chain, Journal of Manufacturing Technology Management, Vol. 22, No. 8, 972-983, doi:10.1108/17410381111177430

[17] Jarvis, J. M.; McDowell, E. D. (1991). Optimal product layout in an order picking warehouse, IIE Transactions, Vol. 23, No. 1, 93-102, doi:10.1080/07408179108963844

[18] Roodbergen, K. J.; De Koster, R. (2001). Routing order pickers in a warehouse with a middle aisle, European Journal of Operational Research, Vol. 133, No. 1, 32-43, doi:10.1016/S03772217(00)00177-6

[19] Petersen, C. G.; Aase, G. (2004). A comparison of picking, storage, and routing policies in manual order picking, International Journal of Production Economics, Vol. 92, No. 1, 11-19, doi:10.1016/j.ijpe.2003.09.006

[20] Burinskiene, A. (2011). The travelling of forklifts in warehouses, International Journal Simulation Modelling, Vol. 10, No. 4, 204-212, doi:10.2507/IJSIMM10(4)4.191

[21] Erkan, T. E.; Can, G. F. (2014). Selecting the best warehouse data collecting system by using AHP and FAHP methods, Technical Gazette, Vol. 21, No. 1, 87-93

[22] Lawler, E. L.; Lenstra, J. K.; Rinnooy Kan, A. H. G.; Shmoys, D. B. (Eds.). (1985). The Traveling Salesman Problem: A Guided Tour of Combinational Optimization, John Wiley \& Sons, Chichester 
Appendix 1: Suggested forklift routing algorithm for "broom effect" implementation in reference warehouse.

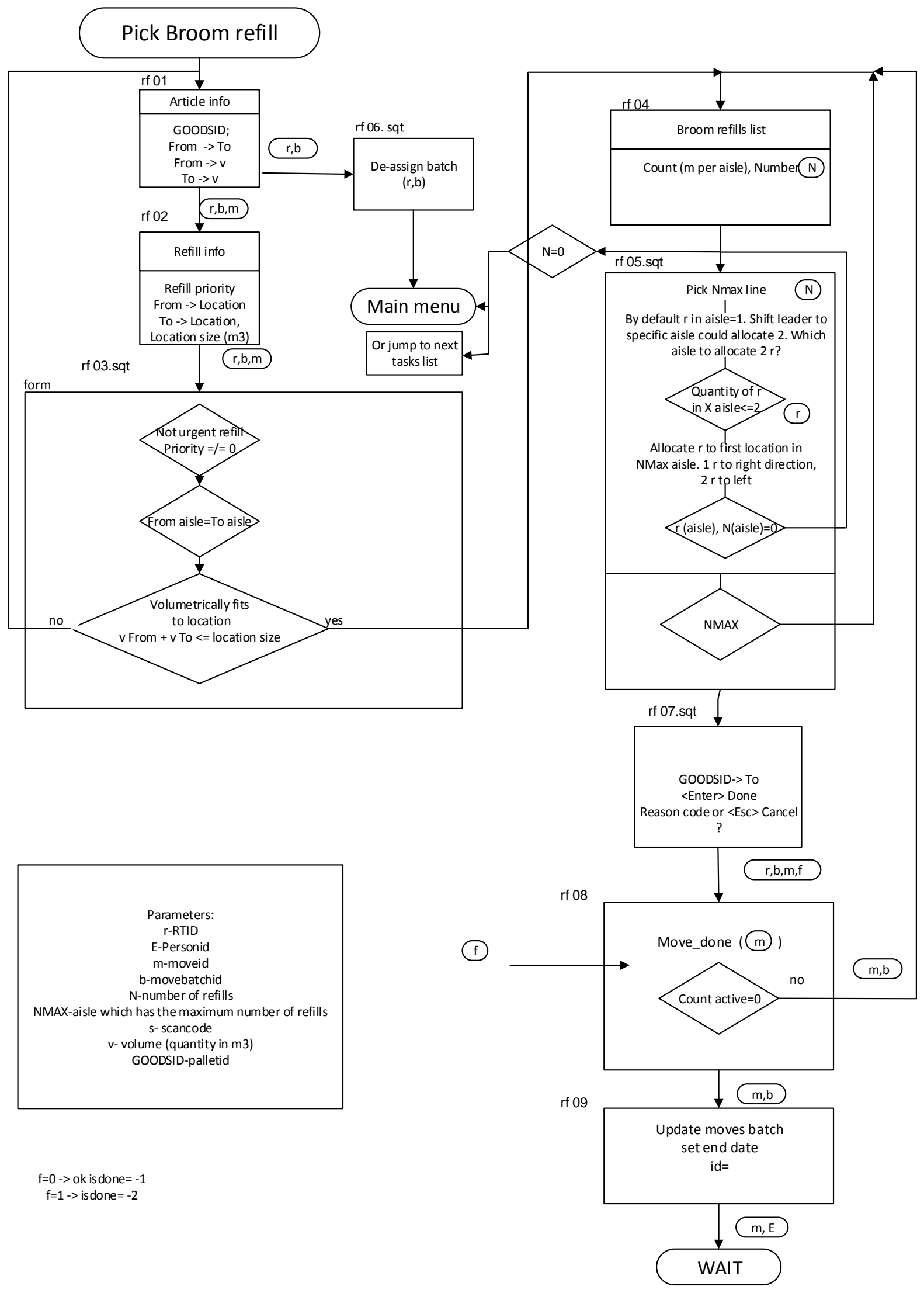

